\title{
Asymmetric Effect of Monetary Policy on Stock Market Volatility in ASEAN5
}

\author{
Trung Thanh BUI*
}

\begin{abstract}
Among many channels, stock market directly transmits the effect of monetary policy decisions because it quickly responds to policy news. The primary objective of this paper is to clarify the asymmetric effect of monetary policy on stock market volatility, which is believed to have adverse effects on the economy recovery, over its bull and bear period. We performed empirical research in a panel setting in which monthly data of ASEAN5 (Vietnam, Thailand, Philippines, Malaysia, and Indonesia) was collected from January 2006 to June 2013. To reduce identification and endogeneity problem, we used short-term interest rate as a proxy for the stance of monetary policy. The Markov switching model was used to identify the bull and bear periods of stock market. We employed feasible GLS estimator to examine the possible asymmetry. The empirical results have demonstrated the existence of the asymmetry in the monetary policy effect on the stock market volatility over stock market cycle in ASEAN5. The findings have suggested that monetary policy is more effective in bear market and that a tight monetary policy increases the probability of shifting stock market from bullish to bearish state.
\end{abstract}

Keywords: Asymmetric Effect, Monetary Policy Transmission, Stock Market Volatility, Monetary Policy, ASEAN5

JEL Code Classification: E4, E5, G1

UDC: [336.761: 303.4.025]: 339.923

\footnotetext{
${ }^{*}$ Faculty of Public Finance, University of Economics Ho Chi Minh City, Vietnam. Email: trungbt@ueh.edu.vn
} 


\section{Introduction}

Macroeconomists have widely accepted that a highly volatile stock market has adverse impacts on the economic recovery. Generally, the volatility of stock return is understood as the uncertainty in the return earned from the stock market over a specific period. It is important information for market participants and policymakers. Accurate estimation of the stock market volatility is crucial for managing risk and trading decisions (Martens \& van Dijk, 2007) and accessing market liquidity (Poon \& Granger, 2003). Moreover, Daly (2008) states that higher volatility can erode confidence in capital market, lead to higher probability of bankruptcy, affect hedging decision, and reduce economic activities and investment.

Policymakers have recognized that the stock market plays an important role in transmitting the effect of monetary policy on the real economic activity. The stock market acts as an important conduit for monetary policy to real activities through channels such as the wealth effect, the investment effect, the balance sheet effect, and the liquidity effect (Mishkin, 1976). In all channels, the effect of monetary policy on the stock market is the first step.

Furthermore, the relation of stock market and monetary policy can be explained through the theory of asset pricing. Accordingly, monetary policy can affect the movement of stock price in two different ways: impact on cash flows and impact on discount rate (Bernanke \& Kuttner, 2005). Monetary policy significantly influences the magnitude and the riskiness of the cash flows generated by firms. Expansionary monetary policy provides firms with greater access to credit, which helps them pursue profitable projects and thus increase their cash flows. Moreover, the fluctuation of the cash flows is rather stable because of favorable business environment during the expansion period. Inversely, a tight monetary policy makes it difficult for firms to access external capital and makes the economy become more volatile.

The asymmetries, in the context of monetary policy, mean that a given monetary policy has inconsistent effects on its objectives depending on circumstances. The literature suggests that the asymmetries in monetary policy effect are well captured by the finance constraint theory. This theory is constructed on the assumption of imperfect capital market. It has two basic properties: (1) time inconsistence involves time wedge between cash inflow and cash outflow and (2) binding finance constraint refers to a sequence of financial pressures faced by a firm during bad economic times. Asymmetric information, which refers to a situation in which the borrowers have more information than lenders about their ability to repay, will increase the cost of funds raised from outside the firm. Therefore, the firm that has higher level of asymmetric information is constrained to their internal funds. Moreover, the binding finance constraint is likely to occur during bear markets. When the market is declining, the net worth of firm is likely to 
fall, which makes the problems of adverse selection and moral hazard more severe. Consequently, the financially constrained firm has to abandon potentially profitable projects, which reduces investments in assets serving as collateral for further borrowing. Hence, binding finance constraint affirms that the effects of monetary policy are greater in bear markets.

Recent literature has documented that stock market inconsistently responds to monetary policy. See for instances Lobo (2000), Bernanke and Kuttner (2005), Chuliá et al. (2010), Guo (2004), Andersen et al. (2007), Basistha and Kurov (2008), and among others. As predicted by the finance constraint theory, the response of stock market to a similar change in monetary policy is stronger in bearish periods. However, these studies have primarily examined the asymmetric response of stock market to monetary policy in developed countries. To the best knowledge of the authors, the study of Zare et al. (2013) is a rare study about the asymmetries in developing countries. Our study contributes to the existing literature by investigating the asymmetric effect of monetary policy on stock market volatility in ASEAN5 (Vietnam, Thailand, Philippines, Malaysia, and Indonesia), which are smallopen developing countries. The findings of this paper answer an intuitive question of whether the effect of monetary policy is inconsistent even in developing world. If the asymmetries exist, the responses of policymakers should not be constant but vary depending on the specific status of the stock market. Another reason that requires further research is the intensive development of stock markets in ASEAN5 in recent years. Since the stock market can directly transmit the effect of monetary policy, our findings provide better insights into the monetary transmission mechanism through stock market in the context of developing countries.

The rest of this paper is organized as follows. Section 2 illustrates the literature about asymmetries in the effect of monetary policy on the stock market. Section 3 presents methodology employed to provide the empirical results about possible asymmetries. Section 4 presents the empirical findings. Section 5 is the conclusion.

\section{Related Literature Review}

The literature has well documented the asymmetries in the effect of monetary policy on various indicators of stock market. A large body of literature has investigated the asymmetries in the response of stock return to the direction of monetary policy shocks (Bernanke \& Kuttner, 2005; Chuliá et al., 2010). Guo (2004), Andersen et al. (2007), and Basistha and Kurov (2008) reported that monetary policy decision had different effects on stock market indicators such as price or return over expansion and contraction period. Several studies examined asymmetries over stock market cycles (Chen, 2007; Jansen \& Tsai, 2010; Kurov, 2010).

The recent growing body of literature pays substantial attention to the asymmetric effect of monetary policy on the volatility of stock market. The reason for this concern is that stock market volatility has adverse effects on the recovery process 
of the economy (Poon \& Granger, 2003; Martens \& van Dijk, 2007; Daly, 2008). One line of research has revealed that stock market responds differently to monetary policy shock. See for instance Bomfim (2003), Konrad (2009), Vähämaa and Äijö (2011), Gospodinov and Jamali (2012), and among others. Consistent with the hypothesis of imperfect capital market, their analysis suggests that only unexpected component of monetary policy decision has impacts on the volatility of stock market. Specifically, a negative shock, which is a decrease in interest rate larger than market expectation, reduces the premium of volatility risk.

Another line of research has focused on the asymmetries over business cycle. Chuliá et al. (2010) have reported the stronger effects of the monetary policy shocks on the volatility of stock market during recessions than during expansions. The rationales are the irrational behavior of market participants and the inefficiency of the capital market. The market participants do not always behave rationally in response to macroeconomic news during bad and good economic times. Specifically, the timing of monetary policy shock is more important during recessions whereas their magnitude is more important during expansions. However, fewer studies have focused on these asymmetries over the cycle of the stock market. To the best of our knowledge, the rare studies about these asymmetries are by Konrad (2009) and Zare et al. (2013). These studies have discovered the stronger impact of monetary policy on the volatility of stock return in bear markets.

Majority of studies reviewed so far have examined the asymmetries in monetary policy effect on the return or volatility of stock market in developed economies and in the setting of time series. However, inappropriate information collection reduces the availability of data about macro-policy variables and market variables in developing countries. This fact raises the need for performing panel data analysis to investigate possible asymmetries in the context of developing countries. Other underlying reason is that information contained in the panel data is richer than that in time-series data.

In a panel setting, Zare et al. (2013) find larger effects of monetary policy on stock market volatility in bear markets. They argue that the finance constraint theory well explains this asymmetry. The presence of asymmetric information increases the cost of external capital, which may create a binding finance constraint during bear markets. Consequently, the effect of monetary policy is stronger in bear markets. However, this study has not taken into account the effect of groupwise heteroskedastisity and cross-sectional dependence in a panel analysis. Our paper employs feasible Generalized Least Square (GLS) estimator developed by Kmenta (1986) to examine the asymmetries in a panel setting. The GLS estimator is an elegant method that provides robust estimation of coefficient and variance in case the assumptions of homoscedasticity and cross-sectional independence are violated. 


\section{Methodology}

This paper examines the asymmetric effect of monetary policy on the stock market volatility by estimating equation(1). The asymmetric effect of monetary policy is defined by comparing the coefficients of monetary policy indicator in bull and bear market, which are the interaction between policy rate (irate) and dummy variable for bull market (bull) and bear market (1-bull). We construct these monetary policy indicators following Kurov (2010), Jansen and Tsai (2010), and Zare et al. (2013). If the coefficients on interaction term, $\beta_{1}$ and $\beta_{2}$, are different and statically significant, the stock market responds differently to a similar change in policy variables over bull and bear period.

$$
\text { avol }_{i t}=\alpha_{i}+\beta_{1} * \text { irate }_{i t} * \text { bull }_{i t}+\beta_{2} * \text { irate }_{i t} *\left(1-\text { bull }_{i t}\right)+\beta_{3} * \text { control }_{i t}+\left(\mu_{i}+\varepsilon_{i t}\right)
$$

\subsection{Estimating stock market volatility}

The volatility of stock market can be defined in many different ways. The most common one is to determine the standard deviation of return that investors can earn from the stock market. However, financial series may experience periods of stably high return or volatilely low return, which is called the cluster effect (Mandelbrot, 1963). This is likely the case in ASEAN5. Guidi and Gupta (2011) have reported the inefficiency of ASEAN stock markets with the exception of the Singapore, which could be considered as a weak form of efficient market. Therefore, the historical volatility and return of stock market in selected countries are important information to forecast the volatility and return of these markets in the future.

Hence, this study uses AutoRegressive Conditional Heteroskedastisity model (ARCH) developed by Engle (1982) to give a more accurate estimation of the stock market volatility. This model captures the cluster effect by dividing the stock market volatility into two parts: a constant term plus weighted square of past residual. The equation (2) is the specification of the $\mathrm{ARCH}(1)$ model.

$$
\operatorname{var}\left(u_{t}\right)=\sigma^{2}=\alpha_{0}+\alpha_{1} u_{t-1}^{2}
$$

\subsection{Identifying the stock market cycle}

This paper examines the asymmetry in monetary policy effect on stock market volatility over stock market cycle. Therefore, it is important to have accurate estimation of bullish and bearish market periods. Currently, two methods could be used for this process: (1) Markov switching model proposed by Hamilton (1989) and (2) nonparametric methodology proposed by Pagan and Sossounov (2003). This paper prefers the first method to identify bull and bear market. The Markov switching model solves unobservable shifts in regimes of stock market by drawing probability inference of each regime based on the behavior of stock market. 
Specifically, the probability of state $S_{t}$ depends on previous states and follows a Markov chain, defined as follows:

$$
p_{i \mid j}=P\left[S_{t+1}=i \mid S_{t}=j\right], i, j=0, \ldots, S-1
$$

After determining the transition probability, the stock market is considered as in bullish period if probabilities are greater than 0.5; otherwise, it is in bear period (Zare et al., 2013).

\subsection{Measuring the monetary policy stance}

The literature has suggested two conventional measures of monetary policy stance. The first approach defines the stance of monetary policy by using monetary aggregates. However, it is difficult to collect data about monetary aggregate. Moreover, money growth rate is endogenous because the policymakers may adjust it to reflect economic development. Because of these drawbacks, researchers need alternative indicators. Compared to monetary aggregate, interest rate is less likely to encounter problems of identification and endogeneity (Bernanke and Blinder, 1992).

\subsection{Estimating asymmetric monetary effect on stock market volatility}

Generally, ordinary least squares (OLS) estimator provides efficient and consistent estimations under the assumptions of homokedastisity and cross-sectional independence. However, these assumptions are commonly violated because of many reasons in the context of panel data analysis. When the disturbances are time-wise autoregressive and cross-sectionally heteroskedastic, the OLS estimations are biased and standard error statistics provide misleading inferences. The GLS model described in Kmenta (1986) provides unbiased estimations under the assumption that the error process is auto-correlated, heteroskedastic, and spatially dependent. GLS model is specified as follows:

$$
\begin{gathered}
y_{i t}=\alpha+x_{i t} \beta+u_{i t} \text { where } i=1, \ldots, N ; t=1, \ldots, T \\
u_{i t}=\rho_{i} u_{i, t-1}+\varepsilon_{i t} \\
\left.\mathbf{E}\left[\varepsilon \varepsilon^{\prime}\right]=\mathbf{\Omega}=\mathbf{\Sigma} \otimes \boldsymbol{I}_{T} \text { where } \varepsilon^{\prime}=\left(\varepsilon_{11}, \ldots, \varepsilon_{1 T}, \ldots, \varepsilon_{N 1}, \ldots, \varepsilon_{N N}\right)\right)
\end{gathered}
$$

Three steps are conducted to get feasible GLS estimation of coefficients (Kmenta, 1986; Baltagi, 2013). The autoregressive parameter $\rho_{i}$ that can be different over panel is firstly estimated by using OLS residuals. Its estimation $\hat{\rho}_{i}$ is then used in a PW transformation to get a consistent estimation of the matrix $\Sigma$, which has an order of $\mathrm{N} \times \mathrm{N}$. Finally, previous estimations are used to provide consistent estimation of regression coefficient and variance. The robust GLS estimation of coefficient and variance are specified in (4)and (5) respectively. 


$$
\begin{gathered}
\hat{\beta}_{G L S}=\left(\mathbf{X}^{\prime} \hat{\mathbf{\Omega}}^{-1} \mathbf{X}\right)^{-1} \mathbf{X}^{\prime} \hat{\mathbf{\Omega}}^{-1} y \\
\operatorname{Var}\left(\hat{\beta}_{G L S}\right)=\left(\mathbf{X}^{\prime} \hat{\mathbf{\Omega}}^{-1} \mathbf{X}\right)^{-1}
\end{gathered}
$$

\subsection{Data description}

This paper uses a balanced panel data of ASEAN5 countries, which includes Vietnam, Thailand, Philippines, Malaysia, and Indonesia. The dataset is collected from Asia Regional Integration Center webpage (http://aric.adb.org/) and from central banks' website on monthly basis, from January 2006 to June 2013. Variety of short-term interest rates are used as measures of the monetary policy stance: refinancing rate in Vietnam, 1-day repurchase rate in Thailand, reverse repo rate in Thailand, overnight interest rate in Philippines, and discount rate in Indonesia. We used composite stock index to identify the states of stock market and to estimate the volatility of stock market. This paper uses monthly data of manufacturing production growth rate (mrate) as a proxy for the domestic output. We further expand the model by including two other relevant variables; namely, exchange rate index (xrate) and inflation rate (frate). According to the theory of asset pricing, these variables have strong impacts on the size and riskiness of the cash flows of the stock. Hence, the inclusion of these variables significantly reduces the bias of omitted variables.

\section{Empirical Results}

\subsection{Examination of stock market volatility}

The ASEAN5 stock markets fluctuated significantly over the period 2006-2013, especially on the aftermath of the global financial crisis (see Figure 1). Among these markets, Vietnam stock market has been the most volatile one. Since late 2009, its volatility has become weaker, but still stronger than that of other countries in the region. As observed, the ASEAN5 stock markets move together after the crisis. The completion of the legal system may explain the increasing integration of these stock markets.

\subsection{Determination of periods of bull and bear market}

As shown in Table 1, the Markov switching model has well identified the cycle of stock market in ASEAN5. The Markov switching model defines bull market and bear market as highly stable return and volatile low return, respectively. Moreover, the transition probability, $\mathrm{p}_{11}$ and $\mathrm{p}_{22}$, shows the high persistence of bull and bear market. Generally, the bearish periods last shorter than the bullish periods in majority of ASEAN5 markets with the exception of Vietnam stock market. 


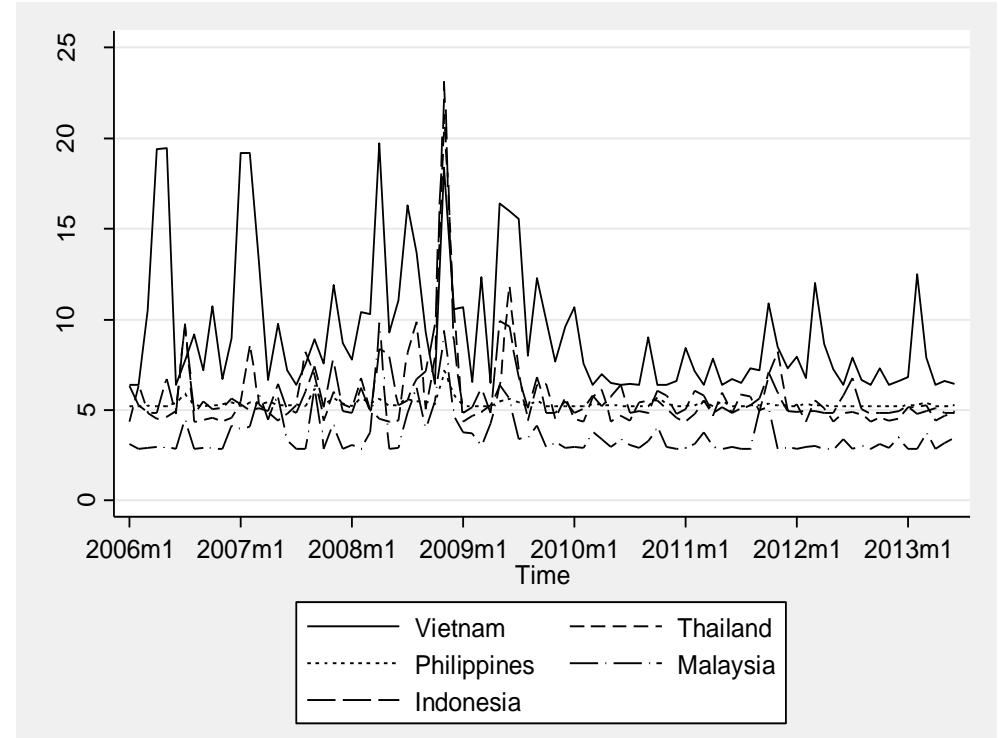

Figure 1: Conditional volatility of stock market return in ASEAN5 estimated by ARCH(1) model.

Table 1: States of stock market defined by Markov switching model

\begin{tabular}{cccccc}
\hline & Vietnam & Thailand & Philippines & Malaysia & Indonesia \\
\hline$\mu_{1}$ & 0.159 & 0.017 & 0.023 & 0.009 & 0.027 \\
$\mu_{2}$ & -0.025 & -0.114 & -0.043 & -0.079 & -.0 .106 \\
$\sigma_{1}$ & 0.021 & 0.005 & 0.004 & 0.006 & 0.005 \\
$\sigma_{2}$ & 0.014 & 0.024 & 0.011 & 0.019 & 0.025 \\
$\mathrm{p}_{11}$ & 0.57 & 0.99 & 0.97 & 0.96 & 0.98 \\
$\mathrm{p}_{22}$ & 0.91 & 0.78 & 0.90 & 0.00 & 0.70 \\
Bull duration & 2.38 & 96.62 & 38.14 & 25.53 & 46.57 \\
Bear duration & 11.55 & 4.60 & 10.68 & 1.00 & 3.39 \\
Log likelihood & 156.91 & 205.27 & 214.63 & 270.22 & 197.33 \\
\hline Source: Author's
\end{tabular}

Source: Author's calculations based on data from ARIC

Figure 2 shows the smoothed transition probability of bull period in ASEAN5 stock markets. Bull (bear) market is likely to occur when the transition probability is greater (less) than 0.5 (Zare et al., 2013). The Vietnam stock market has quickly switched its state. In other words, the duration of bull and bear market in Vietnam is shorter than that of others. Other markets show a high persistence of bull and bear market period. As observed, the bear markets are associated with the 20082009 global financial crisis. 




Figure 2: Markov smoothed transition probability of bull period.

\subsection{Asymmetric effect of monetary policy on stock market volatility}

We perform the GLS estimation that is robust to heteroskedastisity and crosssectional correlation to estimate the equation (1). We examine the asymmetric effect of monetary policy on the stock market volatility by comparing coefficients of interaction term between policy variable and probabilities of bull and bear market. The Table 2 presents the robust GLS estimation of the equation (1). The empirical results indicate that the monetary policy has significantly positive effect on stock market volatility in both bullish and bearish market. Furthermore, it is also evident that the asymmetric effect of monetary policy emerges because $\beta_{1}>\beta_{2}$. This implies that monetary policy has stronger impacts during periods of bear market.

Table 2: Robust GLS estimation of monetary policy effect on stock market volatility

\begin{tabular}{lcc}
\hline & Coefficient & Standard error \\
\hline rbull & $0.191^{* * *}$ & $(0.049)$ \\
rbear & $0.248^{* * *}$ & $(0.057)$ \\
frate & 0.006 & $(0.033)$ \\
mrate & 0.007 & $(0.004)$ \\
xrate & 0.000 & $(0.009)$ \\
cons & $4.248^{* * *}$ & $(1.178)$ \\
rwald & 83590.493 & \\
chi2_bp & 247.307 & \\
\hline
\end{tabular}

Source: Author's calculations based on data from ARIC

Notes: Significance level: ${ }^{*} \mathrm{p}<0.05,{ }^{* *} \mathrm{p}<0.01,{ }^{* * *} \mathrm{p}<0.001$. rwald is the modified Wald statistic and chi2-bp is the Breusch and Pagan statistic. 
The finding that interest rate adjustments have stronger impacts on stock market volatility during bear market is in line with the finance constraint theory. This asymmetry may suggest that firms in ASEAN5 countries find it difficult to obtain external funds during declining markets. The possible reasons may be the inefficiency of financial markets and high level of asymmetric information. It is likely that the firms constrain to internal capital and depend on credit provided by banks during bearish periods. The asymmetry found in this paper is also consistent with the findings of previous studies. In a panel setting, Zare et al. (2013) also revealed this asymmetry and found the significantly positive relationship between interest rates and stock market volatility in five countries of ASEAN. By employing the Pooled Mean Group estimator, this study demonstrated that monetary policy decisions had impacts on stock market volatility only in the long-term. In the shortterm, the monetary policy showed no effects. Other researchers, in time series settings, also found the greater effects of monetary policy decisions on the return and volatility of stock market during bear markets (Konrad, 2009; Jansen \& Tsai, 2010; Kurov, 2010).

However, an interesting feature of our findings is that the monetary policy has significantly impacts on stock market volatility in both states of the stock market. Zare et al. (2013), in a study that is closely related to ours, found that monetary policy had significantly impacts on stock market volatility only in bear markets. Our finding indicates the complication of the conduct of monetary policy in ASEAN5. The policymakers should be careful when implementing a tight monetary policy to cool down the economy during booming periods because this action may have adverse effects on stock markets and financial markets in general.

Generally, the central banks usually raise interest rates during times of high inflation. However, investors may adjust their portfolio holdings to reflect new policy information, which then facilitates more trading and, in turn, increases the volatility of stock market. The investors may allocate their funds to alternative investments when stock markets are perceived riskier. The reduction of funds, in turn, may force firms to a sequence of finance constraints. Hence, a tight monetary policy could increase the probability of moving stock market from bullish state to bearish state.

Furthermore, our findings are contrast with the argument of Bernanke and Gertler (2000) that monetary policy has no effects on the volatility of financial markets. According to Bernanke and Gertler (2000), an inflation targeting policy could achieve objectives of price stability and financial stability simultaneously. They also specify two conditions under which asset price volatility is not concerned: (1) the existence of an efficient capital market and (2) no regulatory distortion. Unfortunately, these conditions generally do not hold, especially in developing world. On the other hand, ASEAN5 countries have not pursed the monetary policy framework of flexible inflation targeting. Therefore, the central bankers in these countries may utilize monetary policy to stabilize the stock markets. 


\subsection{Robustness check}

In this paper, we use the modified Wald statistic (Greene, 2000) for testing groupwise heteroskedastisity and the Breusch and Pagan statistics (Breusch \& Pagan, 1980) for testing cross-sectional dependence. As expected, the last two rows of the Table 2 strongly suggest the presence of heteroskedastisity and crosssectional dependence in the panel.

Furthermore, we also report the unit root results of dependent variable (avol), variables of interest (rbull, rbear), and control variables (frate, xrate, and mrate) in Table 3. We use the Breitung test statistics (Breitung and Das, 2005) that take account of cross-sectional dependence in the context of panel analysis. We reject the null hypothesis of unit root for most variables, except inflation rate (frate) and exchange rate index (xrate).

\section{Table 3: Test for unit root}

\begin{tabular}{lcc}
\hline & robust lamda & p-value \\
\hline avol & $-6.844^{* * *}$ & 0.000 \\
rbull & $-5.105^{* * *}$ & 0.000 \\
rbear & $-5.777^{* * *}$ & 0.000 \\
frate & -0.88 & 0.189 \\
mrate & $-5.943^{* * *}$ & 0.000 \\
xrate & 0.496 & 0.690 \\
\hline
\end{tabular}

Source: Author's calculations based on data from ARIC

Notes: Significance level: $* \mathrm{p}<0.05,{ }^{* *} \mathrm{p}<0.01, * * * \mathrm{p}<0.001$. The Breitung test has the null hypothesis of all series are non-stationery. This table reports the robust statistic that allows crosssectional correlation.

\section{Conclusions}

This paper has examined asymmetries in monetary policy effect on stock market volatility in the ASEAN5 countries, which includes Vietnam, Thailand, Philippines, Malaysia, and Indonesia. We have performed empirical research in a panel setting in which monthly data is collected from January 2006 to June 2013. To alleviate problem of identification and endogeneity, we have used short-term interest rate to indicate the stance of monetary policy. The Markov switching model has been used to identify the bull and bear markets. We have employed feasible GLS estimator to examine the possible asymmetries. The empirical results demonstrate the asymmetry in the monetary policy effect on the stock market volatility over stock market cycle. The finding suggests that monetary policy is more effective in bear market and that policymaker should make monetary policy decision differently depending on the state of stock market. Other interesting finding is that the monetary policy has positive and statistically significant impacts on stock market volatility in both states of stock market. This implies that a tight monetary policy increases the volatility of stock market and hence increases the probability of shifting stock market from bullish states to bearish states. 
Trung Thanh BUI

\section{References}

Andersen, T. G.; T. Bollerslev; F. X. Diebold and C. Vega, (2007) "Real-time price discovery in global stock, bond and foreign exchange markets" Journal of International Economics 73(2): 251-277. http://dx.doi.org/10.1016/j.jinteco.2007.02.004

Baltagi, B. H. (2013) Econometric analysis of panel data. Chichester, West Sussex: John Wiley \& Sons, Inc.

Basistha, A. and A. Kurov (2008) "Macroeconomic cycles and the stock market's reaction to monetary policy" Journal of Banking \& Finance 32(12): 2606-2616. http://dx.doi.org/10.1016/j.jbankfin.2008.05.012

Bernanke, B. and M. Gertler (2000) Monetary policy and asset price volatility, National bureau of economic research.

Bernanke, B. and K. Kuttner (2005) "What Explains the Stock Market's Reaction to Federal Reserve Policy?" The Journal of finance 60(3): 1221-1257. http://dx.doi.org/10.1111/j.15406261.2005.00760.x

Bernanke, B. S. and A. S. Blinder (1992) "The federal funds rate and the channels of monetary transmission" The American Economic Review: 901-921.

Bomfim, A. N. (2003) "Pre-announcement effects, news effects, and volatility: Monetary policy and the stock market" Journal of Banking \& Finance 27(1): 133-151. http://dx.doi.org/10.1016/S0378-4266(01)00211-4

Breitung, J. and S. Das (2005) "Panel unit root tests under cross-sectional dependence" Statistica Neerlandica 59(4): 414-433. http://dx.doi.org/10.1111/j.1467-9574.2005.00299.x

Breusch, T. S. and A. R. Pagan (1980) "The Lagrange multiplier test and its applications to model specification in econometrics" The Review of Economic Studies: 239-253. http://dx.doi.org/10.2307/2297111

Chen, S. S. (2007) "Does monetary policy have asymmetric effects on stock returns?" Journal of Money, Credit and Banking 39(2-3): 667-688. http://dx.doi.org/10.1111/j.00222879.2007.00040.x

Chuliá, H.; M. Martens and D. van Dijk (2010) "Asymmetric effects of federal funds target rate changes on S\&P100 stock returns, volatilities and correlations" Journal of Banking \& Finance 34(4): 834-839. http://dx.doi.org/10.1016/j.jbankfin.2009.09.012

Daly, K. (2008) "Financial volatility: Issues and measuring techniques" Physica A: Statistical $\begin{array}{llll}\text { Mechanics and its } 387(11): & \text { 2377-2393. }\end{array}$ http://dx.doi.org/10.1016/j.physa.2008.01.009

Engle, R. F. (1982) "Autoregressive conditional heteroscedasticity with estimates of the variance of United Kingdom inflation" Econometrica: Journal of the Econometric Society: 987-1007. http://dx.doi.org/10.2307/1912773

Gospodinov, N. and I. Jamali (2012) "The effects of Federal funds rate surprises on S\&P 500 volatility and volatility risk premium" Journal of Empirical Finance 19(4): 497-510. http://dx.doi.org/10.1016/j.jempfin.2012.04.009

Greene, W. H. (2000) Econometric analysis. Upper Saddle River, N.J.: Prentice Hall.

Guidi, F. and R. Gupta (2011) "Are ASEAN stock market efficient? Evidence from univariate and multivariate variance ratio tests" Discussion Papers in Finance No 13.

Guo, H. (2004) "Stock prices, firm size, and changes in the federal funds rate target" The 
Asymmetric Effect of Monetary Policy on Stock Market Volatility in ASEAN5

Quarterly Review of Economics and Finance 44(4): 487-507. http://dx.doi.org/10.1016/j.qref.2003.11.001

Hamilton, J. D. (1989) "A New Approach to the Economic Analysis of Nonstationary Time Series and the Business Cycle" Econometrica 57(2): 357-384. http://dx.doi.org/10.2307/1912559

Jansen, D. W. and C.-L. Tsai (2010) "Monetary policy and stock returns: financing constraints and asymmetries in bull and bear markets" Journal of Empirical finance 17(5): 981-990. http://dx.doi.org/10.1016/j.jempfin.2010.08.002

Kmenta, J. (1986) Elements of econometrics. New York: Macrnilian.

Konrad, E. (2009) "The impact of monetary policy surprises on asset return volatility: the case of Germany" Financial Markets and Portfolio Management 23(2): 111-135. http://dx.doi.org/10.1007/s11408-009-0102-5

Kurov, A. (2010) "Investor sentiment and the stock market's reaction to monetary policy" $\begin{array}{lllll}\text { Journal of Banking \& } \quad \text { Finance } & 34(1): & 139-149 .\end{array}$ http://dx.doi.org/10.1016/j.jbankfin.2009.07.010

Lobo, B. J. (2000) "Asymmetric effects of interest rate changes on stock prices" Financial Review 35(3): 125-144. http://dx.doi.org/10.1111/j.1540-6288.2000.tb01424.x

Mandelbrot, B. B. (1963) "The Variation of Certain Speculative Prices" The Journal of Business 36. http://dx.doi.org/10.1086/294632

Martens, M. and D. van Dijk (2007) "Measuring volatility with the realized range" Journal of Econometrics 138(1): 181-207. http://dx.doi.org/10.1016/j.jeconom.2006.05.019

Mishkin, F. S. (1976) "Illiquidity, consumer durable expenditure, and monetary policy" The American Economic Review: 642-654.

Pagan, A. R. and K. A. Sossounov (2003) "A simple framework for analysing bull and bear markets" Journal of Applied Econometrics 18(1): 23-46. http://dx.doi.org/10.1002/jae.664

Poon, S.-H. and C. W. Granger (2003) "Forecasting volatility in financial markets: A review" Journal of Economic Literature 41(2): 478-539. http://dx.doi.org/10.1257/.41.2.478

Vähämaa, S. and J. Äijö (2011) "The Fed's policy decisions and implied volatility" Journal of Futures Markets 31(10): 995-1010. http://dx.doi.org/10.1002/fut.20503

Zare, R., M. Azali, and M.S. Habibullah (2013) "Monetary Policy and Stock Market Volatility in the ASEAN5: Asymmetries Over Bull and Bear Markets" Procedia Economics and Finance 7: 18-27. http://dx.doi.org/10.1016/S2212-5671(13)00213-X 